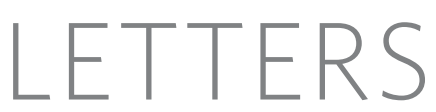

\title{
Myc deletion rescues Apc deficiency in the small intestine
}

\author{
Owen J. Sansom ${ }^{1}$, Valerie S. Meniel ${ }^{2}$, Vanesa Muncan ${ }^{3}$, Toby J. Phesse ${ }^{2}$, Julie A. Wilkins ${ }^{1}$, Karen R. Reed ${ }^{2}$, \\ J. Keith Vass ${ }^{1}$, Dimitris Athineos ${ }^{1}$, Hans Clevers $^{3}$ \& Alan R. Clarke ${ }^{2}$
}

The APC gene encodes the adenomatous polyposis coli tumour suppressor protein, germline mutation of which characterizes familial adenomatous polyposis (FAP), an autosomal intestinal cancer syndrome ${ }^{1}$. Inactivation of $A P C$ is also recognized as the key early event in the development of sporadic colorectal cancers ${ }^{2,3}$, and its loss results in constitutive activity of the $\beta$-catenin-Tcf4 transcription complex ${ }^{3}$. The proto-oncogene $c-M Y C$ has been identified as a target of the Wnt pathway in colorectal cancer cells in vitro ${ }^{4}$, in normal crypts in vivo ${ }^{5}$ and in intestinal epithelial cells acutely transformed on in vivo deletion of the APC gene ${ }^{6}$; however, the significance of this is unclear. Therefore, to elucidate the role Myc has in the intestine after Apc loss, we have simultaneously deleted both $A p c$ and $M y c$ in the adult murine small intestine. Here we show that loss of Myc rescued the phenotypes of perturbed differentiation, migration, proliferation and apoptosis, which occur on deletion of $A p c$. Remarkably, this rescue occurred in the presence of high levels of nuclear $\beta$-catenin. Array analysis revealed that Myc is required for the majority of Wnt target gene activation following Apc loss. These data establish Myc as the critical mediator of the early stages of neoplasia following Apc loss.

We have previously used a conditional gene deletion approach to study the immediate effects of loss of Apc on differentiation, proliferation and migration in the murine small intestine ${ }^{6}$. These studies have shown that loss of Apc leads to unrestricted proliferation within the intestinal crypt, resulting in multiple changes, including an increase in BrdU incorporation, MCM staining and dramatically enlarged crypts at four days post Apc loss ${ }^{6}$. Similar analyses of Myc deficiency have shown remarkably little effect of gene deletion on intestinal proliferation and apoptosis over a five day time course $e^{7,8}$. To examine how Myc affected the phenotypes associated with Apc loss, we intercrossed $A h C r e^{+} A p e^{f l / f l}$ mice with $M y e^{f l f l}$ mice. AhCre mice carry a Cre transgene that is under control of the cytochrome p450 1A1 (CYP1A1) promoter. Mice were given three injections of $\beta$-napthoflavone on a single day, which induces Cre recombinase activity within the intestine. The mice were analysed four days after the first injection. Staining for $\beta$-galactosidase of intestinal whole-mounts from $A h \mathrm{Cre}^{+} \mathrm{Apc} \mathrm{c}^{f l / f l} \mathrm{Myc} \mathrm{c}^{\mathrm{fl} f \mathrm{l}}$ mice carrying the ROSA26 floxed stop cassette lac $Z$ reporter showed near $100 \%$ recombination of the reporter allele, indicating retention of double-mutant Apc-, Myc-deficient crypts (Supplementary Fig. 1a). This highlighted that Cre-mediated deletion of both $M y c$ and Apc was not immediately deleterious to intestinal enterocytes. To confirm that this protocol produced crypts that were both $A p c$ - and $M y c$ deficient we performed immunohistochemistry for Myc and nuclear $\beta$-catenin (a downstream marker of Apc loss). Figure 1a-c shows loss of Myc positivity in crypts by immunostaining and Fig. 1d-f shows nuclear $\beta$-catenin localization consistent with loss of both Apc and $\mathrm{Myc}$ in $\mathrm{AhCre} \mathrm{Apc}^{+\mathrm{flfl}} \mathrm{Myc} \mathrm{fl}^{f l f l}$ intestines.
To confirm co-incident Apc and Myc loss, we performed in situ hybridization for $A p c$ and immunohistochemistry for Myc and $\beta$-catenin in serial sections and saw loss of both Apc and Myc and the appearance of nuclear $\beta$-catenin (Supplementary Fig. 2). Indeed, scoring serial sections revealed combined gene loss in $88.5 \%( \pm 5 \%$ s.d.) of crypts ( $n=3$ mice, 100 crypts scored per mouse). Finally, to show loss of Apc protein, we performed immunofluorescence for Apc (Supplementary Fig. 3). Histological analysis showed that wildtype and doubly deficient crypts were morphologically indistinguishable (Fig. 2a-c). Gross changes associated with Apc deficiency such as the increased crypt cellularity (Fig. 2g), perturbed differentiation (Fig. 2d-f) and an increased number of mitotic figures (Fig. 2h) were absent in the double mutants. To investigate further proliferative changes, we examined levels of BrdU incorporation (Fig. 3a-c) and Ki67 staining (data not shown). In both cases the double-mutant mice did not differ significantly from wild-type mice (MannWhitney $\mathrm{U}$ test; $P=>0.4$ ), and showed lower indices than $A p c$ null tissue and a restoration of the normal proliferation zone (MannWhitney $\mathrm{U}$ test; $P=0.04$ ) (Fig. $3 \mathrm{~d}-\mathrm{f}$ ). We next scored the capacity of double-mutant cells to migrate along the crypt villus axis by comparing the position of BrdU positive cells at 2 and $24 \mathrm{~h}$ after exposure. Remarkably, unlike Apc-deficient cells, migration in the double-mutant mice was normal (Fig. 3f). This rescue explains the presence of cells with nuclear $\beta$-catenin in the double-mutant villi (see Fig. 1f).

Levels of nuclear $\beta$-catenin remained high in the doubly deficient intestines, providing an ideal opportunity to dissect out Mycdependent and -independent targets of the Wnt pathway. We therefore performed microarray analysis with the affymetrix MOE430_2 chip using RNA from $A h \mathrm{Cre}^{+} \mathrm{Apc} c^{f l / f l} \mathrm{Myc} \mathrm{c}^{f l / f l}, \mathrm{AhCre^{+ }} A p c^{f l / f l} \mathrm{Myc}^{+\bar{\gamma}_{+}}$ and $A h \mathrm{Cre}^{+} \mathrm{Apc}^{+/+} \mathrm{Myc}^{+/+}$intestines at four days after gene deletion $^{6}$. The data were analysed using fold change, rank product ${ }^{9}$ and $\mathrm{SAM}^{10}$ (statistical analysis of microarrays) analysis with a false discovery rate (FDR) of no more that 5\%. These analyses indicated significant changes between the three genotypes, listed in Supplementary Tables 1-3. Following only Apc loss, SAM analysis using a 5\% FDR identified 58 genes that had previously been defined by the literature as Wnt target genes ${ }^{11}$ (many are shown at the following website: http://www.stanford.edu/ rnusse/pathways/targets.html). Similar, overlapping gene sets were identified by fold change or rank product analysis (46 known Wnt target genes were increased by 2 -fold or greater; 51 were identified according to rank product analysis). We next examined the expression of these genes in the $A p c^{f l f l} M y c^{f l f l}$ double mutants and found that additional deficiency of Myc blocked the upregulation of the majority of these Wnt target genes (see Supplementary Table 4). Sixty-two per cent of genes (36/58) identified by SAM analysis were significantly downregulated in the double 


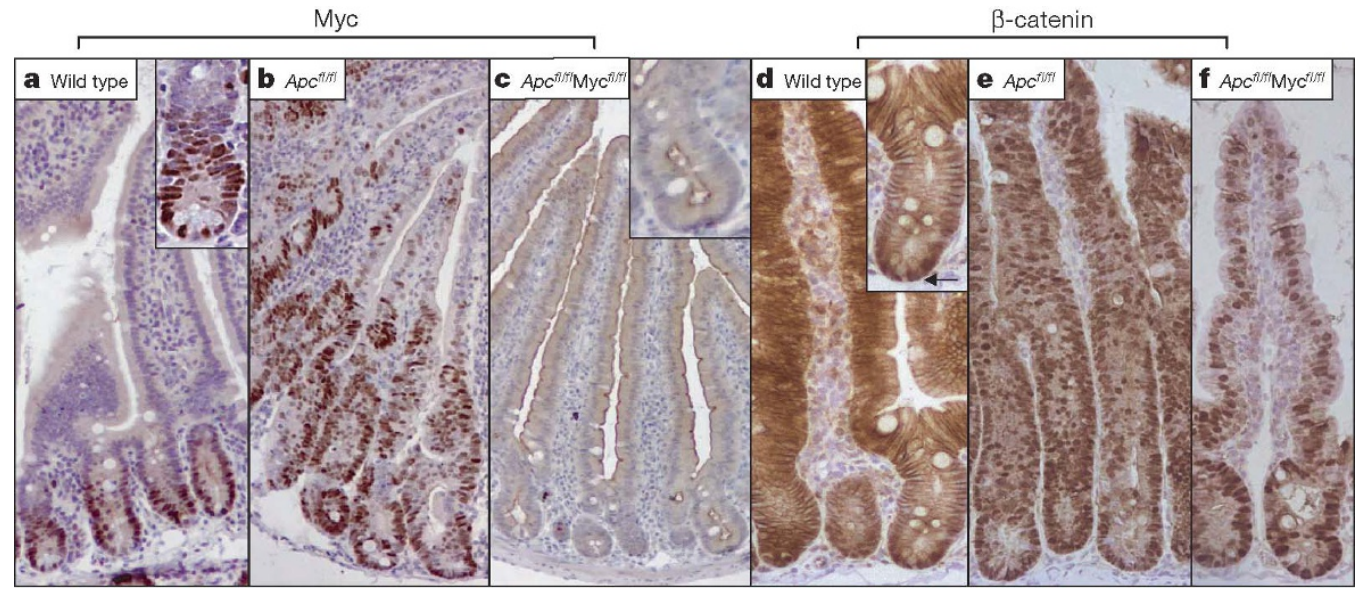

\section{Figure 1 | Efficient deletion of both $A p c$ and Myc from intestinal}

enterocytes. a-c, Myc shown by immunohistochemistry. a, Myc in wildtype crypts $\left(\mathrm{AhCre}^{+} \mathrm{Apc}^{++} \mathrm{Myc}^{++}\right.$mice) at four days post Cre induction. Inset shows nuclear Myc expression at the base of the crypt. b, Upregulation of Myc following Apc loss in Apc-deficient crypts (AhCre ${ }^{+} \mathrm{Apc}^{\mathrm{flfl} l} \mathrm{Myc} \mathrm{c}^{+/+}$ mice) at four days post Cre induction. The immunohistochemistry shows nuclear Myc in every Apc-deficient cell in the crypt. c, Loss of Myc protein in double-mutant crypts $\left(A h C r e^{+} A p c^{f l / f l} M y c^{f l f l}\right)$ at four days following Cre induction. Inset shows that no cells express Myc within the crypt.

d-f, Upregulation of $\beta$-catenin in double-mutant $\left(A h C r e^{+} A p c^{f l / f l} M y c^{f l f l}\right)$ intestines shown by immunohistochemistry. $d, \beta$-catenin is localized at the

knockouts; 27/46 (59\%) were downregulated as assessed by fold change; and 32/51 (62\%) were significantly downregulated according to rank product analysis. These genes include axin2, tcf1, tiam1 (ref. 12) and Sox17, and thus are identified as Myc-dependent (Supplementary Table 4). In contrast, a smaller percentage of these genes (including CD44, Cyclin D2 and Troy) were unaffected by the additional loss of Myc, reflecting Myc independence. We confirmed a subset of these changes by real time quantitative reverse transcriptase (qRT)-PCR (Supplementary Fig. 4). cell edge of nearly all intestinal enterocytes of wild-type crypts $\left(\mathrm{AhCre}^{+} \mathrm{Apc}^{+/+} \mathrm{Myc}^{++}\right.$mice) at four days post Cre induction. Arrow points to the occasional cell which has nuclear $\beta$-catenin at the base of a normal crypt. e, Nuclear localization of $\beta$-catenin in every cell within Apc-deficient crypts $\left(A h C r e^{+} A p c^{f l / f l} \mathrm{Myc}^{+/+}\right.$mice) at four days post Cre induction.

f, Nuclear localization of $\beta$-catenin in every cell within double-mutant crypts (AhCre ${ }^{+} A p c^{f l / f l} M y c^{f l f l}$ mice) at four days post Cre induction. Because

$\beta$-catenin adopts only a nuclear localization throughout the crypt if Apc is deleted, these data argue that in the double-mutant crypts both Apc and Myc are deleted. Magnifications, $\times 400$.

Thus, we define, in an in vivo setting, a subset of Wnt target genes for which Myc is essential. This subset of target genes is critical in imposing the Apc-deficient phenotype. For example, we have previously shown that perturbation of the EphB/EphrinB system, following Apc loss, results in mislocalization of Paneth cells ${ }^{6,13}$. In the double mutants, these Tcf 4 target genes were no longer transcriptionally elevated, and consistent with this, we observed normal localization of the Paneth cells in the double mutants (Fig. 3g-j). Critically, the Wnt target genes that we identify as Myc-independent
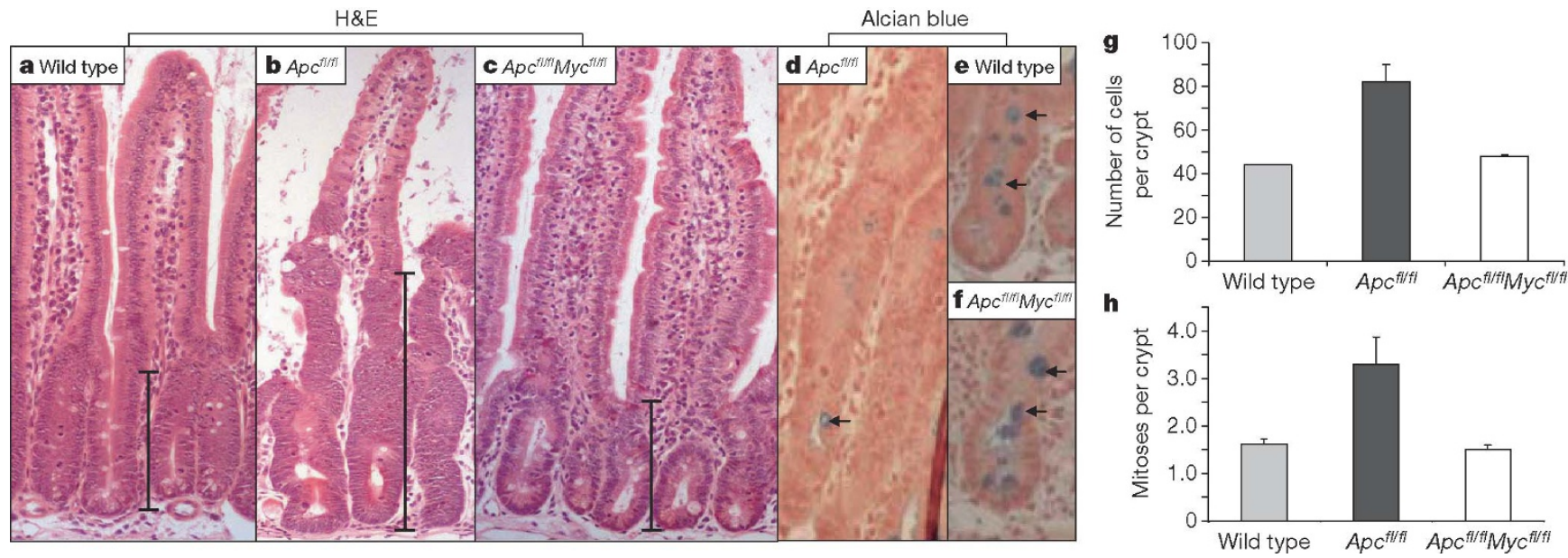

Figure 2 Additional loss of Myc causes Apc-deficient crypts to resemble wild-type crypts. a-c, Haematoxylin and eosin (H\&E)-stained sections for wild-type $\left(\mathrm{AhCre}^{+} \mathrm{Apc}^{+/+} \mathrm{Myc}^{+/+}\right)$(a), Apc-deficient

$\left(A h C r e^{+} A p c^{f l / f l} M y c^{+/+}\right)$(b) and double-mutant Apc- and Myc-deficient $\left(A h C r e^{+} A p c^{f l / f l} M y c^{f l / f l}\right)(c)$ intestines. Note the enlarged crypts in the Apcdeficient mice (b) are no longer present in double-mutant intestines

(c). $\mathbf{d}-\mathbf{f}$, Restored goblet cell number in double-mutant intestines. Alcian blue-stained section for Apc-deficient $\left(A h C r e^{+} A p c^{f l f l} M y c^{+/+}\right)$(d), wild-type $\left(\mathrm{AhCre}^{+} \mathrm{Apc}^{+/+} \mathrm{Myc}^{+/+}\right)(\mathbf{e})$, and double-mutant $\left(A h \mathrm{Cre}^{+} \mathrm{Apc} \mathrm{cllfl}^{f / l} \mathrm{Myc} \mathrm{flfl}^{f l f}\right)$ (f) intestines. Note the reduction in goblet cells that occurs in Apc-deficient crypts does not occur in double-mutant crypts (Mann-Whitney test, $P=0.04, n=3)$. Arrows point to 'blue' goblet cells. g, Crypt cellularity is not increased in double- mutant crypts. Graph showing average cell number per crypt. Error bars, s.d. Unlike Apc-deficient crypts, which have a significantly increased size compared with wild type crypts $(P=0.04$, Mann-Whitney test, $n=3$ ), no difference in size was observed between wild-type and double-mutant crypts (Mann-Whitney test, $P=0.4$ ). $h$, Numbers of mitotic figures per crypt are not increased in double-mutant crypts. Graph showing average number of mitoses per crypt. Error bars, s.d. Unlike Apc-deficient crypts, which have a significantly increased number of mitotic figures per crypt compared with wild-type crypts $(P=0.04$, Mann-Whitney test, $n=3)$, no significant difference was observed between wild-type and double-mutant crypts (Mann-Whitney test, $P=0.303$ ). In all figures $n$ refers to the number of mice analysed. Error bars, s.d. In a-c, scale bars show size of crypt; magnification of $d-f, \times 600$. 
are insufficient to impose the phenotypes associated with Apc deficiency.

In the double mutants, a number of genes associated with DNA and RNA replication were no longer transcriptionally upregulated (for example, DNA polymerase $\varepsilon, M C M 2, M C M 7, B r f 1$, RNA polymerase I subunits, RNA polymerase II, eif4 $\gamma$, and the rRNA genes ( RpS11-13, $S 18$ and L13). Our data are therefore consistent with numerous reports of Myc driving transcription of genes associated with proliferation $^{14}$; however, we cannot rule out the possibility that these changes simply reflect the reduced proliferation that we observe.

Previous studies have postulated that Myc may facilitate proliferation through repression of p21 (ref. 5). This is unlikely to be a direct effect within normal intestinal crypts because there is no induction of p21 and no obvious G1 arrest when Myc is deleted ${ }^{7,8}$. However, repression of $\mathrm{p} 21$ by Myc was demonstrated in colorectal cancer cell lines mutant for Apc, raising the possibility that repression of $\mathrm{p} 21$ may only be important in the context of activated Wnt signalling. To address this, we performed immunohistochemistry for p21 (Fig. $3 \mathrm{k}-\mathrm{m}$ ) and found $\mathrm{p} 21$ to be upregulated within the crypts of double-mutant $A p c^{f l / f l} M y c^{f l f l}$ mice. This argues that the loss of the crypt progenitor-cell-like phenotype in double-mutant mice may be partially due to the inability to repress p21.
Previous reports have suggested that Myc can integrate and balance different survival signals. In certain contexts, Myc expression can lead to proliferation, whereas in other contexts, activation of Myc drives apoptosis ${ }^{15,16}$. Given the failure to see increased proliferation in the double mutants, we next investigated levels of apoptosis in the $A h C r e^{+} A p c^{f l / f l} M y c^{f l / f l}$ intestines. Previously, we have shown that loss of Apc increases the apoptotic index in $A h C r e^{+} A p c^{f l / f l}$ mice. In the double-mutant $A h C r e^{+} A p c^{f l / f l} M y c^{f l / f l}$ intestines this increase was completely blocked (wild type, $0.16 \% \pm 0.05 ; A p c^{f l / f l}, 7.3 \% \pm 0.6$; $A p c^{f l f l} M y c^{f l / f l}, 0.33 \pm 0.13$; Supplementary Fig. 5a), showing Myc dependency for both apoptosis and proliferation, following activation of the Wnt pathway. To investigate further the link between proliferation and death, we pulse-labelled with BrdU and followed the fate of labelled cells. Within wild-type crypts, there was a $43 \%$ increase in the number of labelled cells (as a consequence of division) between 2 and $24 \mathrm{~h}$ (Supplementary Fig. 5b). No such increase was observed in the $\mathrm{AhCre} \mathrm{Apc}^{+} \mathrm{Alfl} M y c^{+/+}$mice, implying that BrdUpositive cells were being deleted (Fig. 4b). This interpretation is further supported by the observation that the mitotic index was not elevated in the $C r e^{+} A p c^{f l f l}$ mice (control, $5.83 \pm 0.27$ s.e.; $\mathrm{Cre}^{+} \mathrm{Apc}^{f l / f l}, 6.43 \pm 1.77 ; P=0.66$, Mann-Whitney test, $n=3$ ), despite the large increase in BrdU labelling, implying that death is
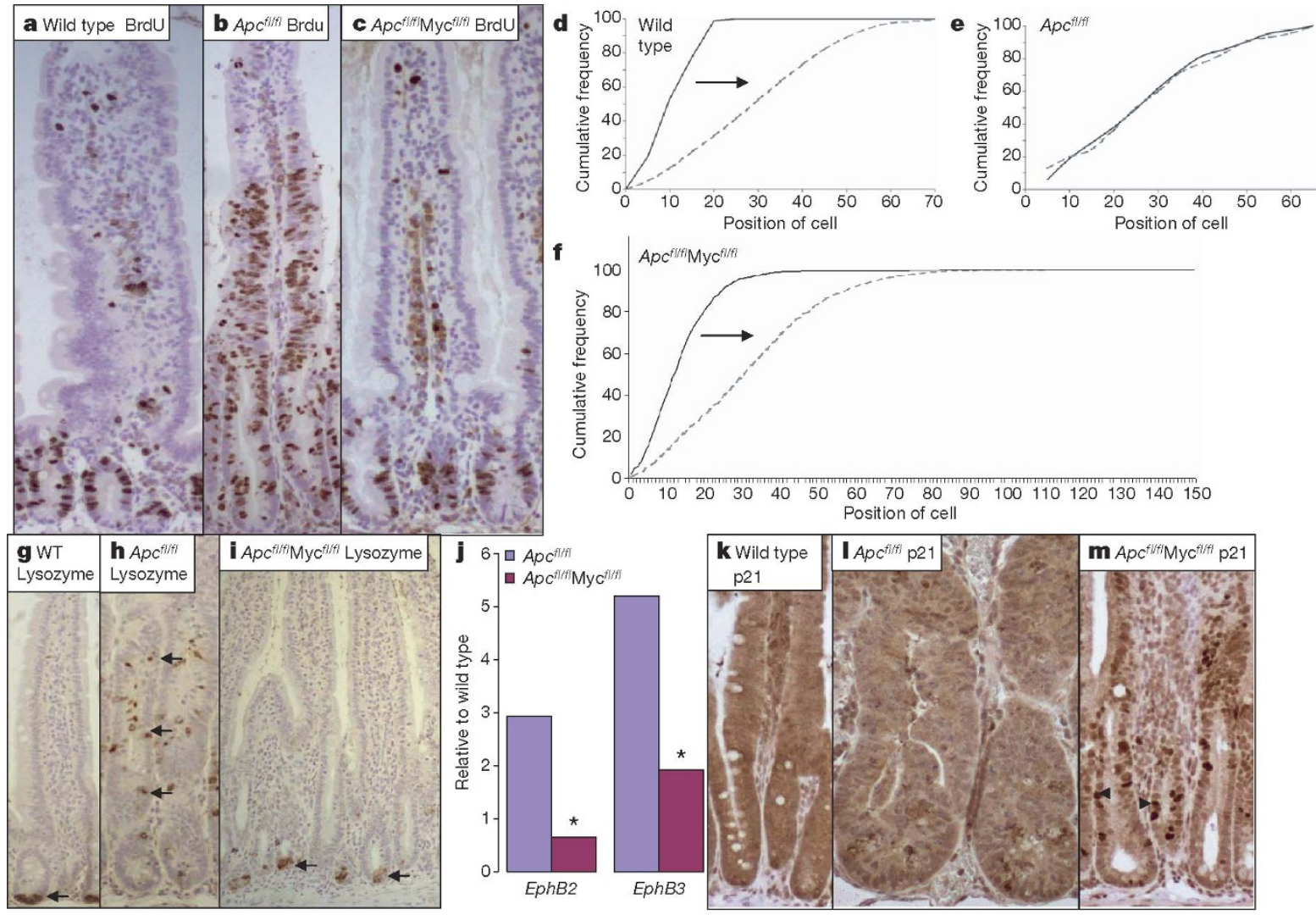

Figure 3 | Additional loss of Myc removes the crypt progenitor-cell-like phenotype of Apc-deficient cells. a-c, Immunohistochemistry for BrdU performed on wild-type $\left(A h C r e^{+} A p c^{+/+} \mathrm{Myc}^{+/+}\right)$(a), Apc-deficient $\left(A h \mathrm{Cre}^{+} A p c^{f l / f l} M y c^{+/+}\right)(\mathbf{b})$ and double-mutant $\left(A h C r e^{+} A p c^{f l / f l} M y c^{f l / f l}\right)$ (c) intestines, at four days after Cre induction and two hours following BrdU injection. Note that wild-type and double-mutant crypts only incorporate BrdU within the crypt, displaying a defined proliferation zone. Apc-deficient crypts have a significantly increased number and percentage of BrdUlabelled cells (Mann-Whitney test, $P=0.04$ ). $\mathbf{d}-\mathbf{f}$, Graphs showing the position of the BrdU-labelled cells $2 \mathrm{~h}$ (black solid line) and $24 \mathrm{~h}$ (grey dashed line) after labelling. In wild-type $\left(\mathrm{AhCre}^{+} \mathrm{Apc}^{+/+} \mathrm{Myc} \mathrm{C}^{+/+}\right)$crypts, cells migrate up the crypt-villus axis from 2 to $24 \mathrm{~h}$; shown here by cells labelling at higher positions on the crypt-villus axis (arrows; Kolmogorov-Smirnov test, $2 \mathrm{~h}$ versus $24 \mathrm{~h}, P=0.01$ ). Within Apc-deficient

$\left(A h \mathrm{Cre}^{+} \mathrm{Apc}^{f l / f l} \mathrm{Myc}^{+/+}\right)$crypts, cells label throughout the crypt-villus axis at
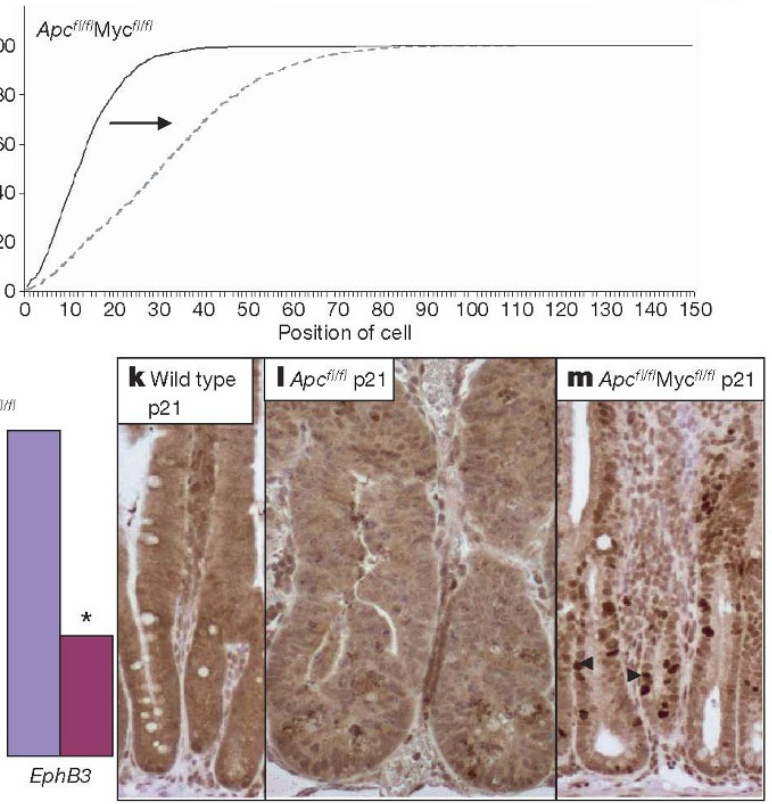

$2 \mathrm{~h}$ and there is no movement $24 \mathrm{~h}$ later (Kolmogorov-Smirnov test, $2 \mathrm{~h}$ versus $24 \mathrm{~h}, P=0.8)$. Within double-mutant $\left(A h C r e^{+} A p c^{f l / f l} M y c^{f l / f l}\right)$ crypts, cells migrated up the crypt-villus axis (Kolmogorov-Smirnov test, $2 \mathrm{~h}$ versus $24 \mathrm{~h}, P=0.01) . \mathbf{g}-\mathbf{i}$, Immunohistochemistry for lysozyme, performed on wild-type (WT; $A h C r e^{+} A p c^{+/+} \mathrm{Myc}^{+/+}$) (g), Apc-deficient $\left(A h \mathrm{Cre}^{+} A p c^{f l / f l} \mathrm{Myc}^{+/+}\right)(\mathbf{h})$ and double-mutant $\left(A h \mathrm{Cre}^{+} A p c^{f l / f l} \mathrm{Myc} c^{f l / f}\right)$ (i) intestines. Positions of lysozyme-positive paneth cells are denoted by arrows. j, Real time qRT-PCR for the EphB2 and EphB3 receptor mRNAs. Note Paneth cells are no longer mislocalized in double-mutant crypts and expression of the EphB2 and EphB3 receptor mRNAs is significantly lower than in Apc-deficient crypts $\left({ }^{*} P=0.04\right.$, Mann-Whitney test).

$\mathbf{k}-\mathbf{m}$, Immunohistochemistry for p21, performed on wild-type (k), Apcdeficient (I) and double-mutant $\left(A h C r e^{+} A p c^{f l / f l} M y c^{f l / f l}\right)(\mathbf{m})$ crypts.

Arrowheads indicate a number of p21-positive cells in double-mutant crypts (m). Magnifications, $\times 400$. 
occurring in either the G2 or $\mathrm{M}$ phases ${ }^{17}$. In accordance with this, many of the apoptotic figures observed were large-a phenomenon previously interpreted to reflect death of $4 n$ cells at a G2/M checkpoint ${ }^{17}$. This is also consistent with reports that Myc upregulation drives cells precociously into $S$ phase ${ }^{18}$ and $\beta$-catenin induces death at the G2/M checkpoint in epidermal keratinocytes in vitro ${ }^{19}$.

To investigate the long-term fate of doubly deficient cells, we intercrossed $A h C r e^{+} A p c^{f l / f l} M y c^{f l / f l}$ mice with mice carrying the ROSA26 lacZR allele ${ }^{20}$ to report Cre-mediated recombination, and exposed them to dietary $\beta$-napthoflavone $\left(0.8 \mathrm{mg} \mathrm{ml}^{-1}\right)$. This approach delivers lower levels of recombination, and allows $A h C r e^{+} A p c^{f l / f l}$ mice to survive sufficiently long to develop adenomas $^{21}$. Notably, this strategy also allows an analysis of the interaction between mutant and wild-type cells because approximately 10\% of crypts undergo recombination. AhCre ${ }^{+} A p c^{f l f l} M y c^{+/+}$and $A h C r e^{+} A p c^{f l / f l} M y c^{f l / f l}$ mice were induced and analysed 20 days later. The $A h \mathrm{Cre}^{+} \mathrm{Apc} \mathrm{c}^{f l f l} \mathrm{Myc} \mathrm{c}^{+/+}$mice develop severe intestinal pathology, with thousands of small lesions and multiple adenomas. In contrast, no double-mutant cells remained in $A h C r e^{+} A p c^{f l / f l} M y c^{f l / f l}$ mice and there was no pathological change. This was confirmed by immunostaining, which failed to identify any crypts that were Myc deficient or that retained nuclear $\beta$-catenin (Supplementary Fig. 6).

We have previously shown that single deficiency of Myc leads to reduced biosynthetic activity and strong selection against Myc-deficient stem cells ${ }^{8}$. We hypothesize that, in the double mutants, surrounding wild-type stem cells outcompete the double-null cells and repopulate the crypts, much as we have seen for other alleles deleted using this strategy ${ }^{22,23}$.

In conclusion, we show that the dramatic changes conferred by Apc deficiency are entirely dependent on functional Myc. Furthermore, given that $\mathrm{Myc}$ is required for the persistence of Apcdeficient cells, these data show that Myc is absolutely required for the cellular and molecular changes that occur following Apc loss in the murine small intestine.

\section{METHODS}

Mouse colonies. All experiments were performed under the UK Home Office guidelines. Outbred male mice from 6-12 weeks of age were used, and they were segregating for the C57BLJ and S129 genomes. The alleles used were as follows: $A p c^{580 S}$ flox (ref. 6), $M y c^{\text {fl/fl }}$ (ref. 8) and AhCre (ref. 22).

Tissue isolation and analysis. To induce recombination, mice were given daily intraperitoneal injections of $\beta$-napthoflavone $\left(80 \mathrm{mg} \mathrm{kg}^{-1}\right)$ for 3 days and harvested 4 days after the first injection. At this time point, mice were killed and the small intestine removed and flushed with water. Intestines were dissected and analyses for apoptosis, mitosis and S-phase labelling were performed on the proximal intestine, as described in Supplementary Methods. In situ hybridization, immunohistochemistry and immunofluorescence were performed as previously described ${ }^{9,11}$. Detailed protocols are given in the Supplementary Methods. To determine the pattern of recombination at the ROSA26R reporter locus, intestinal whole-mounts were prepared, fixed and exposed to X-gal substrate using a method previously reported ${ }^{8,23}$. For microarray analysis, RNA was extracted from $3 \mathrm{~cm}$ of the small intestine that was located $7 \mathrm{~cm}$ from the stomach. For details of RNA extraction, microarray analysis and real time qRT-PCR analysis of targets see Supplementary Methods.

Received 21 September 2006; accepted 9 February 2007.

Published online 21 March 2007.

1. Kinzler, K. W. et al. Identification of FAP locus genes from chromosome 5q21. Science 253, 661-665 (1991).
2. Kinzler, K. W. \& Vogelstein, B. Lessons from hereditary colorectal cancer. Cell 87, 159-170 (1996).

3. Korinek, V. et al. Constitutive transcriptional activation by a $\beta$-catenin-Tcf complex in $\mathrm{APC}^{-/-}$colon carcinoma. Science 275, 1784-1787 (1997).

4. He, T. C. et al. Identification of c-MYC as a target of the APC pathway. Science 281, 1509-1512 (1998).

5. van de Wetering, M. et al. The $\beta$-catenin/TCF-4 complex imposes a crypt progenitor phenotype on colorectal cancer cells. Cell 111, 241-250 (2002).

6. Sansom, O. J. et al. Loss of Apc in vivo immediately perturbs Wnt signaling, differentiation, and migration. Genes Dev. 18, 1385-1390 (2004).

7. Bettess, M. D. et al. c-Myc is required for the formation of intestinal crypts but dispensable for homeostasis of the adult intestinal epithelium. Mol. Cell. Biol. 25, 7868-7878 (2005).

8. Muncan, V. et al. Rapid loss of intestinal crypts on conditional deletion of the Wnt/Tcf-4 target gene c-Myc. Mol. Cell. Biol. 26, 8418-8426 (2006).

9. Breitling, R., Armengaud, P., Amtmann, A. \& Herzyk, P. Rank products: a simple, yet powerful, new method to detect differentially regulated genes in replicated microarray experiments. FEBS Lett. 573, 83-92 (2004).

10. Tusher, V. G., Tibshirani, R. \& Chu, G. Significance analysis of microarrays applied to the ionizing radiation response. Proc. Natl Acad. Sci. USA 98, 5116-5121 (2001).

11. Giles, R. H., van Es, J. H. \& Clevers, H. Caught up in a Wnt storm: Wnt signaling in cancer. Biochim. Biophys. Acta 1653, 1-24 (2003).

12. Malliri, A. et al. The Rac activator Tiam1 is a Wnt-responsive gene that modifies intestinal tumor development. J. Biol. Chem. 281, 543-548 (2006).

13. Batlle, E. et al. $\beta$-catenin and TCF 4 mediate cell positioning in the intestinal epithelium by controlling the expression of EphB/EphrinB. Cell 111, 251-263 (2002).

14. Oskarsson, T. \& Trumpp, A. The Myc trilogy: Iord of RNA polymerases. Nature Cell Biol. 7, 215-217 (2005).

15. Pelengaris, S., Khan, M. \& Evan, G. I. Suppression of Myc-induced apoptosis in $\beta$ cells exposes multiple oncogenic properties of Myc and triggers carcinogenic progression. Cell 109, 321-334 (2002).

16. Green, D. R. \& Evan, G. I. A matter of life and death. Cancer Cell 2002, 19-30 (2002).

17. Merritt, A. J., Allen, T. D., Potten, C. S. \& Hickman, J. A. Apoptosis in small intestinal epithelia from $p 53$-null mice: evidence for a delayed, p53-independent G2/M-associated cell death after $\gamma$-irradiation. Oncogene 14, 2759-2766 (1997).

18. Li, Q. \& Dang, C. V. c-Myc overexpression uncouples DNA replication from mitosis. Mol. Cell. Biol. 19, 5339-5351 (1999).

19. Olmeda, D., Castel, S., Vilaro, S. \& Cano, A. $\beta$-catenin regulation during the cell cycle: implications in G2/M and apoptosis. Mol. Biol. Cell. 14, 2844-2860 (2003).

20. Soriano, P. Generalized lacZ expression with the ROSA26 Cre reporter strain. Nature Genet. 21, 70-71 (1999).

21. Sansom, O. J. et al. Cyclin D1 is not an immediate target of $\beta$-catenin following Apc loss in the intestine. J. Biol. Chem. 280, 28463-28467 (2005).

22. Ireland, H. et al. Inducible Cre-mediated control of gene expression in the murine gastrointestinal tract: effect of loss of $\beta$-catenin. Gastroenterology 126, 1236-1246 (2004).

23. Hay, T., Patrick, T., Winton, D., Sansom, O. J. \& Clarke, A. R. Brca2 deficiency in the murine small intestine sensitizes to p53-dependent apoptosis and leads to the spontaneous deletion of stem cells. Oncogene 24, 3842-3846 (2005).

Supplementary Information is linked to the online version of the paper at www.nature.com/nature.

Acknowledgements. This work was supported by the CR-UK. Thanks to D. Scarborough and Beatson technology services (T. Gilby, M. O'Prey and A. Dawson) for help with histology, M. Bishop for genotyping and K. Vousden for comments. Thanks also to Y. Hey and the PICR for microarray analysis.

Author Contribution: O.J.S., V.S.M., V.M., K.R.R., T.J.P. J.A.W., J.K.V. and D.A. conducted research for the paper. O.J.S., H.C. and A.R.C. wrote the paper. All authors discussed the results and read the paper.

Author Information: Reprints and permissions information is available at www.nature.com/reprints. The authors declare no competing financial interests. Correspondence and requests for materials should be addressed to O.J.S. (o.sansom@beatson.gla.ac.uk). 